\title{
PENILAIAN MENOPAUSAL RATING SCALE (MRS) PADA WANITA MENOPAUSE DI KOTA PEMATANGSIANTAR TAHUN 2019
}

\author{
Dame Evalina Simangunsong \\ Poltekkes Kemenkes Medan \\ email :dameevalinas8@gmail.com
}

\begin{abstract}
Climacterium syndrome is a collection of symptoms experienced by a woman who started at the end of the reproductives until the five years after menopause. This time is a difficult time that women must be passed on with different complaints from each individual. The complaint can be categorized into four complaints such as physical complaints, vasomotor complaints, psychosocial complaints, urogenital complaints. Various complaints experienced can decrease the quality of life of women. Complaints experienced by menopause women can be assessed by Menopausal Rating Scale (MRS).This research is a descriptive type of research with a crosssectional design that aims to determine the description of menopausal complaints experienced by menopausal women in two locations in Pematangsiantar City. The results of the study illustrate that women who are examined in two research locations experience menopausal complaints in the weight category, especially in psychological and urogenital complaints. There is a health care effort in women before the menopause arrives. It is very important to prepare women in receiving the menopause and face the various complaints that will be experienced.
\end{abstract}

Key words: Climacterium; MRS

\begin{abstract}
ABSTRAK
Sindrom klimakterium berupa kumpulan gejala yang dialami oleh seorang wanita yang dimulai pada akhir masa reproduktif hingga masa lima tahun setelah menopause. Masa ini merupakan suatu masa sulit yang harus dilewati oleh wanita dengan berbagai keluhan yang berbeda tiap individu. Keluhan yang dialaminya dapat golongkan atas empat keluhan seperti keluhan fisik, keluhan vasomotor, keluhan psikososial, keluhan urogenital. Berbagai keluhan yang dialami dapat menurunkan kualitas hidup wanita. Keluhan yang dialami wanita menopause ini dapat dinilai dengan Menopausal Rating Scale (MRS). Penelitian ini adakah penelitian jenis deskrikpif dengan design crosssectional yang bertujuan untuk mengetahui gambaran keluhan menopause yang dialami wanita menopause di dua lokasi yang ada di Kota Pematangsiantar. Hasil penelitian menggambarkan bahwa wanita yang diteliti pada dua lokasi penelitian mengalami keluhan menopause dalam kategori berat terutama pada keluhan psikologis dan urogenital. Disarankan adanya suatu upaya pelayanan kesehatan pada wanita sebelum masa menopause tiba. Hal ini sangat penting guna mempersiapkan wanita di dalam menerima masa menopause dan menghadapi berbagai keluhan yang akan dialaminya.
\end{abstract}

Kata Kunci $\quad$ : Klimakterium; MRS 


\section{PENDAHULUAN \\ Latar Belakang}

Berbagai keluhan yang dialami wanita pada masa perimenopause di mulai dari gejala ringan sampai berat (gejala fisik dan psikologis) yang dikenal dengan sindroma klimakterik. Masa ini akan dialami seorang wanita berlangsung sejak usia 35-65 tahun yang digolongkan atas klimaterik awal, perimenopause dan klimakterik akhir, masa ini merupakan masa peralihan normal yang disertai dengan penurunan fungsi generative. $^{1}$

Gejala utama sindroma klimakterik wanita Indonesia meliputi gangguan fisik berupa nyeri otot atau sendi $(77,7 \%)$, rasa letih dan hilang energi $(68,7 \%)$, kehilangan nafsu seksual $(61,3 \%)$, kerutan di kulit $(60 \%)$, sulit konsentrasi dan hot flushes $(29,5 \%)$, jantung berdebar-debar $40 \%$, kurang tenaga $65 \%$, berkunang-kunang $20 \%$, kesemutan $25 \%$, obstipasi $40 \%$, berat badan bertambah $60 \%$. Gangguan psikologis dapat berupa, gangguan tidur $50 \%$, depresi $70 \%$, mudah tersinggung, berasa takut, gelisah dan lekas marah 90\%, sakit kepala 70\%, cepat lelah, sulit konsentrasi, mudah lupa,. Sebanyak $70 \%$ wanita peri dan pasca menopause mengalami sindroma klimakterik pada kurun usia 45- 54 tahun. Usia ratarata menopause perempuan di Indonesia $48 \pm 5,3$ tahun. $1,2,3$

Siregar (2014), menilai sindroma klimakterium pada 100 orang paramedis RSUP Haji Adam Malik Medan dengan menggunakan Menopause Rating Scale (MRS), menemukan keluhan rasa tidak nyaman pada persendian dan otot sebanyak 47 orang $(84 \%)$ pada kelompok perimenopause dan 50 orang $(100 \%)$ dari pascamenopause. Keluhan somatis ringan ditemukan pada kelompok perimenopause 22 orang (44\%), dan pada kelompok pasca menopause sebagian besar dengan keluhan somatis ringan dan keluhan urogenital berat, masing-masing sebanyak 31 orang $(62 \%){ }^{4}$

Gejala cemas pada pascamenopause sedikit lebih tinggi (40,3\%) dibandingkan kelompok perimenopause $(33,8 \%)$, gejala depresi pada pascamenopause lebih tinggi $(20,8 \%)$ dibandingkan kelompok perimenopause $(13,8 \%)$ pada paramedis RSUP. H. Adam Malik. ${ }^{5}$

Usia harapan hidup wanita di Indonesia tahun 2018 berkisar 71 tahun, sementara rata-rata kejadian menopause pada usia 51 tahun. Dihadapkan dengan berbagai keluhan yang muncul pada masa tersebut, masa menopause menjadi masalah yang serius. Ditambah lagi dengan proyeksi jumlah penduduk yang menopause pada tahun 2025 diperkirakan akan ada sebanyak 60 juta orang. ${ }^{6}$

Hasil survey yang dilakukan pada 20 wanita menopause yang ada di kota Pematangsiantar tentang keluhan yang dialami, sebanyak 18 orang wanita menopause menyatakan lebih dari lima jenis keluhan menopause yang dirasakan setiap harinya dan sangat mengganggu aktivitasnya sehari-hari. Hal ini menjadi dasar dilakukannya penelitian, tentang bagaimana karakteristik wanita menopause di Kota Pematangsiantar.

\section{Tujuan Penelitian}

Penelitian ini bertujuan untuk menegetahui karakteristik ibu menopause dan menilai keluhan menopause yang dialami dengan menggunakan skala penilaian Menopausal Rating Scale (MRS)

\section{METODE}

Jenis penelitian adalah penelitian deskriptif dengan menilai keluhan menopause dengan penilaian Menopause Rating Scale (MRS) terhadap 70 wanita yang telah menopause di dua keluhrahan yang ada di Kota pematangsiantar.

\section{Lokasi dan Waktu Penelitian}

Penelitian dilakukan di Kota Pematangsiantar, di Kelurahan Kahean Kecamatan Siantar Utara dan Kelurahan Timbang Galung Kecamatan Siantar Barat.

Pemilihan lokasi penelitian ini didasarkan kepada besarnya jumlah penduduk (wanita yang berusia 50 tahun ke atas) yang ada pada 8 kecamatan yang ada di Kota Pematangsiantar.

\section{Waktu Penelitian}

Penelitian ini telah dimulai dengan pengumpulan data awal sejak Juli sampai dengan Agustus 2018.

\section{Populasi dan Sampel}

Populasi dalam penelitian ini adalah wanita yang telah menopause yang tinggal di Kota Pematangsiantar. Subjek yang diikutkan dalam penelitian adalah yang bersedia mengikuti penelitian dengan mengisi surat persetujuan mengikuti penelitian (informed consent). Tehnik penarikan sampel dilakukan dengan tehnik purposive sampling dengan pertimbangan sebagai berikut :

1. Kriteria Inklusi :

a. Wanita yang telah menopause

b. Tidak mengalami pengangkatan ovarium dan rahim

c. Tidak sedang menjalani pengobatan dan program diet

2. Kriteria Eksklusi

a. Wanita yang mengalami menopause dini

b. Wanita yang mengalami osteoporosis

c. Wanita yang sedang menjalani pengobatan hormon

\section{Besar Sampel ${ }^{7}$}

Besar sampel dihitung menggunakan rumus sampling pada tingkat kepercayaan $95 \%\left(\mathrm{Z}_{1-\alpha / 2}=1,96\right)$ dengan kekuatan uji $90 \%\left(\mathrm{Z}_{1-\beta}=1,282\right)$, asumsi proporsi kelompok tidak terpapar $\left(\mathrm{P}_{2}\right) \quad 50 \%$ dan perkiraan risiko relatif (RR) sebesar 1,75 (Lemeshow et al. 1997) sebagai berikut :

$$
n=\frac{\left\{Z_{1-\alpha / 2} \sqrt{2 P(1-P)}+Z_{1-\beta} \sqrt{(P 1(1-P 1)+P 2(1-P 2)}\right\}^{2}}{(P 1-P 2)^{2}}
$$

Dimana : $\quad \mathrm{P}_{1}=(\mathrm{RR}) \mathrm{P}_{2}=(1,75) 0,5 .=0,88$

$$
\begin{aligned}
& \mathrm{P}=\left(\mathrm{P}_{1}+\mathrm{P}_{2}\right) / 2 \\
= & (0,88+0,5) / 2=0,69
\end{aligned}
$$


$n=\frac{\{1,96 \sqrt{2.0,69(1-0,69)}+1,282 \sqrt{(0,88(1-0,88)+0,5(1-0,5)}\} \begin{array}{c}\text { Karakteristik Wanita Menopause di Kelurahan } \\ \text { Kahean dan Timbang Galung Berdasarkan }\end{array}}{(0,88-0,5)^{2}}$ Riwayat Obstetri di Kota Pematangsiantar 2018

$\mathrm{n}=29,98 \sim 30$

Jumlah sampel yang diperoleh sebanyak 30 orang dan untuk menghindari sampel yang drop out atau loss to follow up, maka besar sampel maksimal yang diambil 35 orang masing-masing di dua kelurahan yang telah ditetapkan.

Alat pengumpul data dan pengukurannya dalam penelitian ini dapat diuraikan sebagai berikut : Menopause Rating Scale ${ }^{8}$

Keluhan menopause diukur dengan menggunakan kuesioner Menopause Rating Scale yang telah baku. Masing-masing pertanyaan memiliki nilai antara $0-4$ (skala Likert). Dari 11 item pertanyaan didapatkan jumlah skore 0-44. Pengukuran dikelompokkan berdasarkan skore yang diperoleh. Semakin tinggi skor, semakin tinggi keluhan menopause.

\section{Hasil Penelitian}

Analisis univariat digunakan untuk melihat distribusi frekuensi wanita menopause di Kelurahan Kahean dan Timbang Galung Kota Pemantangsiantar. Karakteristik responden berdasarkan umur, pendidikan, pekerjaan, siklus haid, usia menikah, paritas, indeks massa tubuh (IMT), dapat dilihat pada table di bawah ini.

Tabel 1

Karakteristikwanita Menopause di Kelurahan Kahean dan Timbang Galung Kota Pematangsiantar 2018

\begin{tabular}{|c|c|c|c|c|}
\hline \multirow[t]{2}{*}{$\begin{array}{c}\text { Karakteristik } \\
\text { Responden }\end{array}$} & \multicolumn{2}{|c|}{ Kahean } & \multicolumn{2}{|c|}{$\begin{array}{c}\text { Timbang } \\
\text { Galung }\end{array}$} \\
\hline & $\begin{array}{c}\mathbf{n} \\
(35)\end{array}$ & $\%$ & $\begin{array}{c}\text { n } \\
(35)\end{array}$ & $\%$ \\
\hline \multicolumn{5}{|l|}{ Usia } \\
\hline 48-50 tahun & 13 & 37,1 & 14 & 40 \\
\hline 51-54 tahun & 22 & 62,9 & 21 & 60 \\
\hline \multicolumn{5}{|l|}{ Pendidikan } \\
\hline $\begin{array}{l}\text { Rendah } \\
\text { (SD,SMP,SLTA) }\end{array}$ & 19 & 54,3 & 19 & 54,3 \\
\hline $\begin{array}{l}\text { Tinggi } \\
\text { (D1,D3,S1,S2) }\end{array}$ & 16 & 45,7 & 16 & 45,7 \\
\hline Pekerjaan & & & & \\
\hline Tidak Bekerja & 18 & 51,4 & 24 & 68,6 \\
\hline Bekerja & 17 & 48,6 & 11 & 31,4 \\
\hline
\end{tabular}

Tabel di atas menunjukkan kelompok usia wanita menopause di kelurahan Kahean yang terbanyak pada golongan usia 51-54 tahun ada sebanyak 62,9\%, demikian juga di kelurahan Timbang Galung ada sebesar $60 \%$. Tingkat pendidikan wanita menopause di Kelurahan Kahean dan Timbang Galung yang terbanyak dengan tingkat pendidikan SD-SMP masingmasing ada sebesar 54,3\%. Sebagian besar wanita menopause tidak bekerja, 51,4 \% di Kelurahan Kahean dan 68,6 \% di Kelurahan Timbang Galung.

Tabel 2

\begin{tabular}{|c|c|c|c|c|}
\hline \multirow{2}{*}{$\begin{array}{c}\text { Riwayat } \\
\text { Obsteri }\end{array}$} & \multicolumn{2}{|c|}{ Timbang Galung } & \multicolumn{2}{|c|}{ Kahean } \\
\hline & $\mathrm{f}$ & $\%$ & $\mathrm{f}$ & $\%$ \\
\hline \multicolumn{5}{|l|}{ Siklus Haid } \\
\hline Normal & 31 & 88,6 & 23 & 65,7 \\
\hline Tidak Normal & 4 & 11,4 & 12 & 34,3 \\
\hline \multicolumn{5}{|l|}{ Usia Menikah } \\
\hline$\leq 20$ thn & 3 & 8,6 & 4 & 11.4 \\
\hline$>20$ thn & 32 & 91,4 & 31 & 88,6 \\
\hline \multicolumn{5}{|l|}{ Paritas } \\
\hline$\leq 2$ org & 7 & 20 & 8 & 22,8 \\
\hline$>2$ org & 28 & 80 & 27 & 77,2 \\
\hline
\end{tabular}

menopause lebih banyak mempunyai riwayat siklus haid yang normal baik di Kelurahan Kahean dan Timbang Galung, mempunyai riwayat usia menikah pertama kali di atas usia 20 tahun serta mempunyai paritas lebih dari dua orang.

Tabel 3

Distribusi Indeks Massa Tubuh (IMT)

Wanita Menopause di Kelurahan Kahean dan Timbang Galung Berdasarkan Riwayat Obstetri di Kota Pematangsiantar 2018

\begin{tabular}{lcccc}
\hline \multicolumn{1}{c}{ IMT } & \multicolumn{2}{c}{ Kahean } & \multicolumn{2}{c}{ Timbang Galung } \\
& $\mathrm{f}$ & $\%$ & $\mathrm{f}$ & $\%$ \\
\hline Normal & 1 & 2,9 & 1 & 2,9 \\
Gemuk & 18 & 51,4 & 7 & 20 \\
Obesitas & 16 & 47,5 & 27 & 77,1 \\
\hline
\end{tabular}

Tabel di atas menunjukkan wanita menopause mempunyai IMT dalam kategori Gemuk dan Obesitas ada sebanyak 97,1 \% baik Kelurahan Kahean dan Timbang Galung.

Tabel 4

Distribusi Skor Keluhan Menopause pada wanita Menopause di Kelurahan Kahean Kota Pematangsiantar

\begin{tabular}{|c|c|c|}
\hline $\begin{array}{l}\mathrm{N} \\
\mathrm{O}\end{array}$ & Keluhan menopause & $\begin{array}{c}\text { Penilaian } \\
\text { MRS }\end{array}$ \\
\hline & & Mean \pm SD \\
\hline 1 & $\begin{array}{l}\text { Badan terasa sangat panas, } \\
\text { berkeringat }\end{array}$ & $1,97 \pm 0,8$ \\
\hline 2 & Rasa tidak nyaman pada & $2.0 \pm 0,8$ \\
\hline
\end{tabular}
jantung (detak jantung yang tidak biasa, jantung berdebar)

3 Masalah tidur (susah tidur, susah untuk tidur nyenyak, bangun terlalu pagi)

4 Perasaan tertekan (merasa tertekan, sedih, mudah menangis, tidak bergairah/lesu), mood yang berubah ubah

$5 \quad$ Mudah marah (merasa gugup, 3,06 $\pm 0,69$ rasa marah, agresif)

6 Rasa resah (rasa gelisah, rasa $3,20 \pm 0,47$ panik)

7 Kelelahan fisik dan mental $3,17 \pm 0,57$ (menurunnya kinerja secara
$3,23 \pm 0,65$

$3,17 \pm 0,57$ 
umum, berkurangnya daya

ingat), menurunnya

konsentrasi,mudah

lupa/pikun)

8 Masalah-masalah seksual

(perubahan dalam gairah

seksual, aktifitas seksual dan

kepuasan seksual

9 Masalah-masalah pada

kandung dan saluran kemih (sulit buang air kecil, sering buang air kecil, buang air kecil yang tidak terkontrol)

10 Kekeringan pada vagina (rasa kering atau terbakar pada vagina, kesulitan dalam berhubungan intim)

11 Rasa tidak nyaman pada persendian dan otot (sakit pada persendian, keluhan rematik)

$3,14 \pm 0,49$

$2.97 \pm 0,66$

$3,34 \pm 0,48$

Tabel di atas menunjukkkan sebaran skor keluhan menopause ; sebaran berdasarkan keluhan fisik (MRS 3,11) diperoleh data bahwa keluhan yang dialami, rata-rata berada pada kategori berat ; keluhan vasomotor (MRS 1 dan 2) diperoleh data bahwa keluhan yang dialami, rata-rata berada pada kategori keluhan menengah ; keluhan psikososial (MRS 4,5,6,7) diperoleh data bahwa keluhan yang dialami, rata-rata berada pada kategori berat ; keluhan urogenital (MRS $8,9,10$ ) diperoleh data bahwa keluhan yang dialami berada pada kategori sangat berat pada keluhan saluran kemih dan rasa tidak nyaman pada persendian dan otot.

\section{Tabel 5}

Distribusi Skor Keluhan Menopause pada wanita Menopause di Kelurahan Timbang Galung Kota Pematangsiantar

\begin{tabular}{|c|c|}
\hline $\begin{array}{l}\mathrm{N} \\
\mathrm{o}\end{array}$ & Keluhan menopause \\
\hline 1 & erkeringat \\
\hline 2 & $\begin{array}{l}\text { Rasa tidak nyaman pada jantung (detak } \\
\text { jantung yang tidak biasa, jantung } \\
\text { berdebar) }\end{array}$ \\
\hline 3 & $\begin{array}{l}\text { Masalah tidur (susah tidur, susah untuk } \\
\text { tidur nyenyak, bangun terlalu pagi) }\end{array}$ \\
\hline 4 & $\begin{array}{l}\text { Perasaan tertekan (merasa tertekan, } \\
\text { sedih, mudah menangis, tidak } \\
\text { bergairah/lesu), mood yang berubah } \\
\text { ubah }\end{array}$ \\
\hline 5 & $\begin{array}{l}\text { Mudah marah (merasa gugup, rasa } \\
\text { marah, agresif) }\end{array}$ \\
\hline 6 & Rasa resah (rasa gelisah, rasa panik) \\
\hline 7 & \begin{tabular}{lccc} 
Kelelahan & fisik & dan & mental \\
(menurunnya & kinerja & secara & umum, \\
berkurangnya & daya & ingat), \\
menurunnya & \multicolumn{2}{c}{ konsentrasi,mudah } \\
lupa/pikun) & \multicolumn{2}{c}{}
\end{tabular} \\
\hline 8 & $\begin{array}{l}\text { Masalah-masalah seksual (perubahan } \\
\text { dalam gairah seksual, aktifitas seksual } \\
\text { dan kepuasan seksual }\end{array}$ \\
\hline 9 & $\begin{array}{l}\text { Masalah-masalah pada kandung dan } \\
\text { saluran kemih (sulit buang air kecil, }\end{array}$ \\
\hline
\end{tabular}

Mean \pm SD

$2,11 \pm 0,72$

$2,09 \pm 0,82$

$2,6 \pm 1,14$

$2,69 \pm 1,13$

$2,66 \pm 0,80$

$2,86 \pm 0,77$

$2,66 \pm 0,94$

$2,74 \pm 0,82$

$2,23 \pm 0,88$ sering buang air kecil, buang air kecil yang tidak terkontrol)

10 Kekeringan pada vagina (rasa kering atau terbakar pada vagina, kesulitan dalam berhubungan intim)

11 Rasa tidak nyaman pada persendian dan otot (sakit pada persendian, keluhan rematik)

Tabel di atas menunjukkkan sebaran skor keluhan menopause ; sebaran berdasarkan keluhan gejala somato-vegetatif (MRS 1,2,3,11) diperoleh data bahwa keluhan yang dialami, rata-rata berada pada kategori keluhan menengah hingga kategori berat; keluhan psikososial (MRS 4,5,6,7) diperoleh data bahwa keluhan yang dialami, rata-rata berada pada kategori berat; keluhan urogenital (MRS 8,9,10) diperoleh data bahwa keluhan yang dialami berada pada kategori berat.

\section{Pembahasan}

Responden dalam penelitian ini adalah wanita menopause yang dipilih sesuai dengan kriteria inklusi. Hasil analisis menunjukkan usia responden pada yang terbanyak berusia 51-54 tahun, sebanyak 22 orang $(62,9 \%)$ di kelurahan Kahean dan 21 orang $(60 \%)$ di Kelurahan Timbang Galung. Masa klimakterium atau masa peralihan dalam kehidupan normal seorang wanita sebelum mencapai senium, yang mulai dari akhir masa reproduktif dari kehidupan sampai masa non-reproduktif yang digolongkan atas klimakterik awal (35-45 tahun), perimenopause (46-55 tahun) dan klimakterik akhir (56-65 tahun). ${ }^{1}$ Wanita yang diteliti dalam penelitian ini berada pada fase perimenopause, dimana pada fase ini keluhan menopause masih banyak dijumpai.

Masa perimenopause seorang wanita merupakan masa antara usia 46-55 tahun, dimana ada dua masa yang dilewati pada periode ini yaitu masa sebelum menopause dan masa setelah menopause. Periode ini merupakan puncak dirasakannya keluhan klimakterium yang dapat berlangsung 4-5 tahun sebelum haid dan 3 tahun setelah berhenti haid. Guna menurunkan keluhan yang dirasakan wanita menopause perlu di intervensi dengan berbagai latihan fisik yang dalam penelitian ini, melatih kekuatan otot tulang dan sendi dalam mengatasi keluhan yang dialaminya.

Hasil analisis menunjukkan sebagian besar latar belakang pendidikan wanita menopause pada kelompok intervensi dan kontrol adalah pendidikan rendah (SD, SLTP, SLTA), masing masing ada sebanyak 19 orang $(54,3 \%)$. Faktor pendidikan sangat berkaitan dengan perubahan perilaku. Semakin tinggi tingkat pendidikan wanita menopause maka akan lebih mudah wanita mengenali masalah yang akan dihadapinya sebagai dampak dari kehilangan hormon estrogen, menyadari bahwa masalah tersebut akan dialami sehingga mampu menerima dan berusaha melakukan upaya pencegahan sedini mungkin dengan tetap menjaga gaya hidup sehat sehingga dapat melalui perubahan yang akan dialami bahkan dapat menjaga kualitas hidup dengan mandiri hingga lanjut usia. 
Berdasarkan analisis pekerjaan, didapatkan ibu tidak bekerja ada sebanyak 18 orang $(51,4 \%)$ di Kelurahan Kahean dan di Kelurahan Timbang Galung juga ibu tidak bekerja ada sebanyak 24 orang $(68,6 \%)$. Ibu yang tidak bekerja di harapkan mampu mengatasi keluhan menopause yang dialaminya karena mempunyai waktu yang lebih banyak dalam mengatasi keluhan yang dialami.

Berdasarkan analisis siklus haid, didapatkan data pada ke-2 lokasi penelitian wanita menopause mempunyai siklus haid normal (28 hari) ada sebanyak 31 orang $(88,6 \%)$, di Kelurahan Kahean dan sebanyak 23 orang $(65,7 \%)$ di Kelurahan Timbang Galung. Deskripsi siklus haid pada kedua kelompok menunjukkan bahwa siklus haid 28 hari atau siklus normal dapat menghilangkan faktor perancu terhadap gangguan berbagai sistim reproduksi pada proses haid dan kehamilannya.

Berdasarkan analisis usia menikah, pada kedua kelompok penelitian, pada kelurahan Kahean terbanyak menikah pada usia $>20$ tahun ada sebanyak 32 orang $(91,4 \%)$ dan di Kelurahan Kahean ada sebanyak 27 orang $(77,2 \%)$. Usia menikah dapat menginformasikan matang tidaknya sistem reproduksi wanita untuk dibuahi. Wanita yang menikah pada usia muda $<20$ dan $>35$ tahun akan mempunyai lebih banyak faktor risiko terhadap kesehatan reproduksinya.

Berdasarkan analisis paritas, didapatkan di Kelurahan Kahean yang terbanyak dengan paritas $>2$ orang ada sebanyak 28 orang $(80 \%)$ demikian juga di Kelurahan Timbang Galung ada sebanyak 27 orang $(77,2 \%)$. Banyaknya paritas seorang ibu dapat memprediksi usia menopausenya, semakin banyak paritasnya, usia menopause akan semakin lama.

Berdasarkan indeks massa tubuh (IMT), mayoritas berada pada kategori gemuk, di Kelurahan Kahean ada sebanyak 18 orang $(51,4 \%)$ dan di Kelurahan Timbang Galung terbanyak berada pada kategori obesitas, sebanyak 22 orang (77,1\%). Keadaan ini menunjukkan bahwa wanita menopause saat dilakukan penelitian sudah mengalami fluktuasi hormon yang berarti dan walaupun sebagian dari responden mengakui bahwa mereka sering mengabaikan frekuensi makan yang teratur dan kerap mengabaikan waktu sarapannya.

Wanita yang berat badannya naik lebih mungkin mengalami penurunan kualitas hidup. Body Mass Index (BMI) yang lebih tinggi berkorelasi dengan skor yang lebih tinggi dari gejala menopause. ${ }^{9}$ Peningkatan Indeks Massa Tubuh (IMT) dikaitkan dengan penurunan kesehatan atau hubungan kegemukan dengan penyakit kronis dan juga perubahan tekanan darah. ${ }^{10}$

Keluhan menopause yang dialami subyek. penelitian di dua lokasi penelitian menunjukkan bahwa keluhan yang dialami, digolongkan pada kategori berat pada keluhan psikososial (MRS 4,5,6,7) dan keluhar. urogenital (MRS 8,9,10). Keluhan psikologis berupa keluhan seperti perasaan tertekan (merasa tertekan, sedih, mudah menangis, tidak bergairah/lesu), mood yang berubah ubah, mudah marah (merasa gugup, rasa marah, agresif), rasa resah (rasa gelisah, rasa panik), kelelahan fisik dan mental (menurunnya kinerja secara umum, berkurangnya daya ingat), menurunnya konsentrasi, mudah lupa/pikun).

Perjalanan hidup dalam kurun usia 40-50 tahun merupakan pengalamam krisis dalam diri seorang wanita, dimana akan menjadi tua dan mengalami menopause. Masa ini sangat kompleks bagi wanita karena berkaitan dengan keadaan fisik dan kejiwaannya. Selain mengalami stress fisik, stress psikologi pun dapat dialami yang mempengaruhi keadaan emosinya.

Keluhan psikologis dapat terjadi ketika seorang wanita tidak siap menerima keadaannya yang sudah mulai menua dan akan mengalami mati haid wanita perimenopause berpikiran negatif memasuki fase ini, banyak wanita mengalami ketidakstabilan emosi seiring dengan kecemasannya dalam mengalami perubahan pada tubuh. Perubahan psikologis juga sangat mempengaruhi kualitas hidup seorang wanita dalam menjalani masa menopause. Perubahan yang terjadi pada wanita menopause adalah mudah merasa tegang, ketegangan ini dapat menimbulkan gejala pada fisik dan psikis, termasuk menjadi pelupa, kurang dapat memusatkan perhatian, mudah cemas, mudah marah dan depresi. ${ }^{11}$

Penurunan kadar estrogen sangat berperan terhadap fungsi susunan saraf pusat, terutama perilaku, suasana hati serta fungsi kognitif dan sensorik seseorang. Kekurangan streroid seks dapat dianggap sebagai faktor predisposisi terjadinya depresi. ${ }^{12}$ Tingkat pengetahuan tentang menopause mempunyai hubungan dengan tingkat kecemasan yang dialami wanita. Pengetahuan yang kurang akan membuat wanita jatuh pada keadaan depresi berat. Pemberian konseling, pendidikan, advokasi dan perawatan diri sangat penting guna menghindari pemahaman dan sikap negatif terhadap menopause sehingga masa menopause akan dapat dilalui dengan baik. ${ }^{13}$

\section{Kesimpulan dan Saran}

Wanita menopause di dua lokasi penelitian mengalami keluhan menopause yang digolongkan pada keluhan somato-vegetatif, psikologik dan urogenital mulai dari keluhan dengan kategori menengah hingga berat.

Dibutuhkan suatu upaya pelayanan kesehatan pada masa menopause agar wanita menopause mampu menerima keadaan yang dialami dan dapat mengatasi keluhan menopause secara mandiri sehingga dapat menjalani aktivitas hariannya dengan normal.

\section{Daftar Pustaka}

Anwar, M., Baziad, A., \& Prabowo, R.P., 2011, Ilmu Kandungan. Jakarta: Bina Pustaka Sarwono Prawirohardjo

Lestary D., 2010, Seluk Beluk Menopause. Jogjakarta: Graha Ilmu. 
3. Prawirohardjo S. 2014, Dalam Wiknjosastro H (Editor). Ilmu Kebidanan. Edisi 5. Jakarta: Tridasa Printer.

4. Siregar, MFG., 2014, Perimenopausal and Postmenopausal Complaints in Paramedics Assesed by Menopause Rating Scale in Indonesia, IOSR Journal of Dental and Medical Sciences (IOSR-JDMS)e-ISSN: 2279-0853, p-ISSN: 2279-0861.Volume 13, Issue 12 Ver. I (Dec. 2014), PP 38-42

5. Silitonga HN, Siregar MFG, Hutapea H, Nasution S. 2010, Depresi dan Cemas Masa Perimenopause dan Pascamenopause Pada Paramedis RSUP H Adam Malik dan RS Jejaring Medan.

6. Badan Pusat Statistik, 2013, Proyeksi Penduduk Indonesia, Population Projetion 2010-2035, Badan Perencanaan Pembangunan Nasional, Jakarta

7. Lemeshow, S., Hosmer, D.W., Klar, J.,Lwanga, S.K. 1997, Besar Sampel dalam Penelitian Kesehatan. Jogjakarta: Gajahmada University Press.

8. Heinemann LAJ, Potthoff P, Schnieder HPG 2003. International versions of Menopause Rating Scale (MRS), Health and Quality of Life Outcomes 1:28-31.

9. Moilanen JM, Aalto AM, Raitanen J, Hemminki E, Aro AR, Luoto R., 2012, Physical activity and change in quality of life during menopause--an 8-year followup study, Health and Quality of Life Outcomes BioMed Central 10:8

10. Hermastuti., 2012, Hubungan Indeks Masa Tubuh, Masa Lemak Tubuh, Asupan kalsium, Aktifitas fisik dan Kepadatan tulang Wanita Dewasa muda (Jurnal of Nutrision College), Semarang, Universitas Diponegoro

11. Sriwaty I., Nuryoyo S., 2014, Pengaruh Psikoedukasi Menopause Dan Relaksasi Untuk Menurunkan Kecemasan Wanita Pre Menopause, Humanitas vol. 12 no. 1 . 29-38, ISSN 1693-7236

12. Speroff L, Glass RH, Kase NG. Menopause and Postmenopausal Hormone Therapy. In Clinical Gynaecology Endocrinology and Infertility. Eighth Edition. Lippincott William \& Wilkins, Philadelphia, 2015; $5: 583-650$

13. Almeida, O.P., Marsh K., Flicker L., Hickey M., FordA., Sim M., 2014, Reducing Depression During The Menopausal Transition: Study Protocol For A Randomised controlled Trial, Biomed Central, Journal Trials $2014,15: 312$ 